\title{
Therapeutic Potential of Mesenchymal Stem Cells and Vitamin E on Experimental Hepatocellular Carcinoma
}

\section{Ragaei $A^{1}$, Mansy $A^{2}$ and Sabry $D^{3 *}$}

${ }^{1}$ Oral and Dental Medicine, General Histology, Future University, Egypt

${ }^{2}$ General Histology, Banha University, Egypt

${ }^{3}$ Medical Biochemistry and Molecular Biology, Cairo University, Egypt

\begin{abstract}
Purpose: This study evaluated the influence of human mesenchymal stem cells (h-MSCs) and/or vitamin E (vit E) on experimental hepatocellular carcinoma (HCC).
\end{abstract}

Methods: Eighty five rats were divided into; group 1: twenty rats served as control group and group 2: sixty five rats received Diethyl Nitrosamine (DENA) followed by carbon tetra chloride $\left(\mathrm{CCl}_{4}\right)$ to induce $\mathrm{HCC}$. Five rats were scarified after 2 months to assess the induction of HCC. The other sixty rats were further subdivided into; group 2: fifteen HCC were untreated rats, group 3: fifteen HCC rats were treated by injection of $107 \mathrm{~h}$-AMSCs, group 4: fifteen HCC rats were treated by vitamin E and group 5: fifteen HCC rats were treated by injection of 107 h-AMSCs and vitamin E. Histological, arginase-1 immunohistochemical examination were assessed and serum albumin and a-fetoprotein were estimated.

Results: Histopathological examination of group 2 revealed presence of anaplastic carcinoma, focal nodular hyperplasia. Group 5 showed improvement in histopathological picture relative to group 3 and 4 . Positive arginase-1 $\mathrm{IHC}$ reaction was observed in group 2 with decrease reactivity in all other groups.

Conclusion: Combined treatment with h-AMSCs and vitamin E has tumor suppressive effect with ameliorating $\mathrm{HCC}$ histopathological picture and liver function.

Keywords: Human amniotic MSCs; Vitamin E; HCC; Arginase-1

\section{Introduction}

Hepatocellular Carcinoma (HCC) is the fifth most common primary liver cancer. The annual number of discovered cases of HCC worldwide is over one million. Globally, HCC is the third leading cause of cancer related death, preceded only by the lung and stomach cancers $[1,2]$. The incidence of HCC has been increasing in Egypt in the past 10 years [3]. HCC contributes to $14.8 \%$ of all cancer mortality in Egypt. Effective and established chemotherapeutic agents for HCC are unavailable with high rate of recurrence. The prognosis of HCC is still poor [4]. A recent research report characterized a new immunohistochemical biomarker, arginase-1, as a potential marker of hepatocellular differentiation in both surgical pathology and cytopathology specimens. Arginase exists in two isoforms, namely arginase-1 and arginase-2, both of which are considered for the hydrolysis of arginine to ornithine and urea in the urea cycle. Arginase-1 demonstrates high levels of expression within the liver, while arginase-2 levels are highest in the kidneys and pancreas and are very low in the liver [5,6]. Mesenchymal Stem Cells (MSCs) are known as a self renewal multipotent and exhibit high potential efficacy for differentiation into different cells/tissue lineages, including cartilage, bone, adipose tissue, tendon, and ligament [7]. Human Amniontic Mesenchymal Cells (hAMSCs) exhibit properties that make them an attractive choice as a cell-mediated therapy in human malignancies [8]. hAMSCs are adult stem cells that exhibit rapid proliferation ex-vivo, and can be differentiated into cell types derived from all three primary germ layers of the embryo in the culture. hAMSCs can be expanded from the discarded placenta after birth, and they possess low immunogenicity allowed them to be used in a range of clinical applications [9]. The inhibition of tumor growth by MSCs has been observed in different types of animal models. In experimental models of Lewis lung carcinoma and B16 melanoma (mouse melanoma cell line), Maestroni et al. were the first to report that the co-injection of mouse MSCs with melanoma cells inhibited growth of primary tumor
[10]. The anti-proliferative action of MSCs was reported in a model of colon carcinogenesis in rats, in which the co-injection of MSCs with tumor cells in a gelatin matrix implanted subcutaneously led to growth inhibition. In addition, this implantation triggered a more pronounced infiltration of monocytes and granulocytes [7].

Among all the natural health supplements, Vitamin $\mathrm{E}$ ( $\alpha$-Tocopherol) exhibits the most intensively studied cancer preventive agent because of its antioxidant property [11]. It refers to a compound, which is able to donate electron and neutralize free radicals, resulting in scavenging and preventing cell injuries. Polyphenol antioxidants, like anthocyanines and tannins, possess the unpaired electron which is delocalized by resonance of aromatic rings to cause better stability and less reactivity rather than by other antioxidants. Furthermore, the toxicity of polyphenols is less than that of destroyed free radicals [12]. There is a hypothesis that oxidative DNA damage lights up the initial stage of carcinogenesis. For instance, hydroxyl radicals hurt DNA and create a series of structurally changed purine and pyrimidine bases with a high degree for mutagenicity. However Vitamin $\mathrm{E}$ as a natural dietary antioxidant may possess anticancer activities on their own by inhibiting protein kinase $C_{7}[13,14]$. We aimed to assessarginase- 1 as

*Corresponding author: Dina Sabry, Faculty of Medicine, Professor of Medical Biochemistry and Molecular Biology, Cairo University, Egypt, Tel: +2-02-23632297; Fax: +2-02-23632297; E-mail: dinasabry@kasralainy.edu.eg

Received August 18, 2016; Accepted September 24, 2016; Published September 30,2016

Citation: Ragaei A, MansyA, Sabry D (2016) Therapeutic Potential of Mesenchymal Stem Cells and Vitamin E on Experimental Hepatocellular Carcinoma. J Stem Cell Res Ther 6: 362. doi: 10.4172/2157-7633.1000362

Copyright: ( 2016 Ragaei A, et al. This is an open-access article distributed unde the terms of the Creative Commons Attribution License, which permits unrestricted use, distribution, and reproduction in any medium, provided the original author and source are credited. 
an early diagnostic molecular biomaker in HCC. We also investigated the suppressive antitumor genesis effects of $\mathrm{h}$-AMSCs on progression of HCC and the ameliorative influence of Vitamin $\mathrm{E}$ in increasing the therapeutic efficacy of the stem cells in HCC treatment.

\section{Methods}

\section{Animal groups}

Eighty five adult male white albino rats with matched age $(6$ months) and weight (200-250 gm) were included in the study. Animals were inbred in the experimental animal unit, Faculty of Medicine, Cairo University. Rats were maintained according to the standard guidelines approved by the Institutional Animal Care and Use Committee of Cairo University.

Animals were fed on a semi-purified diet that contained $\mathrm{gm} / \mathrm{kg}$ : 200 casein, 555 sucrose, 100 cellulose, 100 fat blends and 35 mineral mix [15]. They were divided into:

Group 1 (Control group): 20 rats received normal balanced diet and $3 \mathrm{ml} / \mathrm{kg}$ body weight castor oil twice weekly for 5 months, animals were scarified according to experiment schedule at 2,3,4 and 5 months; five rats in each scarification parallel with other groups.

HCC induced groups: 65 rats received a single intraperitoneal injection of Diethyl Nitrosamine (DENA) at a dose of $200 \mathrm{mg} / \mathrm{kg}$ body weight followed by twice weekly subcutaneous injections of carbon tetra chloride $\left(\mathrm{CCl}_{4}\right)$ at a dose of $3 \mathrm{ml} / \mathrm{kg}$ body weight [16]. Five rats of that group were scarified after 2 month; blood samples and liver specimen were collected to assess the induction of HCC. The other 60 rats were further subdivided into:

Group 2 (HCC untreated group): 15 rats were untreated and served as positive control model and scarified according to experiment schedule.

Group 3 (HCC/h-AMSCs treated group): 15 rats treated by a single injection of $10^{7}$ human amniotic-MSCs/rat intravenously (through tail vein) and scarified according to experiment schedule [17].

Group 4 (HCC/vitamin E treated group): 15 rats treated by oral administration of $10 \mathrm{mg} / \mathrm{kg}$ a-tocopherol acetate (Vitamin E) dissolved in $2 \mathrm{ml} / \mathrm{kg}$ body weight castor oil daily and scarified according to experiment schedule $[18,19]$.

Group 5 (HCC/h-AMSCs and vitamin E treated group): 15 rats treated by injection of $10^{7}$ human amniotic-MSCs (through tail vein) and oral $10 \mathrm{mg} / \mathrm{kg}$ body weight $\alpha$-tocopherol acetate (Vitamin E) dissolved in $2 \mathrm{ml} / \mathrm{kg}$ body weight castor oil daily and scarified according to experiment schedule.

Both histological and immunohistochemical examination of liver tissue, in addition to serum levels of albumin and $\alpha$-fetoprotein were estimated in all groups.

\section{Human mesenchymal stem cells isolation}

Human amniotic membranes were mechanically separated from placentas taken from normal full-term uncomplicated elective cesarean sections after obtaining a written informed consent. They were transported in cold phosphate buffer saline (PBS; Gibco/Invitrogen, Grand Island, New York, USA) solution in a thermally insulated container on ice. The amniotic membrane was washed extensively with PBS to remove contaminating debris and red blood cells. Then the amniotic membrane was minced with scissors and subjected to enzymatic digestion with collagenase II in PBS for 60 minutes at $37^{\circ} \mathrm{C}$ with gentle agitation, mechanical filtration through a strainer and cultured under standard conditions. The separated cells were centrifuged for 10 minutes at $200 \times \mathrm{g} \mathrm{rpm}$ at $10^{\circ} \mathrm{C}$. Isolated MSCs were cultured on $25 \mathrm{ml}$ culture flasks in Minimal Essential Medium (MEM) supplemented with 15\% Fetal Bovine Serum (FBS) and incubated for 2 hours at $37^{\circ} \mathrm{C}$ and $5 \% \mathrm{CO}_{2}$. Adherent MSCs were cultured in MEM supplemented with $30 \% \mathrm{FBS}, 0.5 \%$ penicillin, streptomycin and at $37^{\circ} \mathrm{C}$ in $5 \% \mathrm{CO}_{2}$ in air [20].

\section{Labeling stem cells with GFP}

At 4th passage, MSCs were harvested and labeled with green fluorescent protein (GFP) (amaxa GmbH, amaxa Inc. Europe/World USA Scientific Support) [13]. Human MSC were nucleofected using the human MSC Nucleofector Kit and a plasmid encoding the fluorescent protein GFP according to manufacture instructions. GFP in human amniotic-MSCs (labeled stem cells in vitro) and in unstained rat liver tissues (for tracing of labeled h-MSCs in vivo) was analyzed using inverted fluorescence microscopy (Leica, Germany).

\section{Histopathological examination}

Liver tissues were collected and divided into two sections. The first section was frozen dissected and unstained for tracing of injected labeled cells with GFP. The second section was washed with PBS and fixed overnight in $40 \mathrm{~g} / \mathrm{L}$ paraformaldehyde at $4^{\circ} \mathrm{C}$. Serials $5 \mu \mathrm{m}$ sections of the dissected liver tissues were stained with hematoxylin and eosin (H\&E) [21] and Masson trichrome stain [22] for histopathological studies.

\section{Immunohistochemical staining procedure for arginase-1}

Four-micron thick sections of the formalin-fixed, paraffinembedded tissue blocks of all the studied specimens were investigated for the presence of a rabbit polyclonal antibody against arginase- 1 of rat origin (H-52: sc 20150, Santa Cruz, Europe) at a dilution 1:200 with a labelled streptavidin- biotin-peroxidase complex technique. Briefly, Tissue sections were deparaffinized and hydrated in xylene and descending grades of alcohol. After rinsing in PBS, antigen retrieval was performed by treating the tissue sections with citrate buffer, $\mathrm{pH} 6.0$ for $10 \mathrm{~min}$ in a $700-\mathrm{W}$ microwave oven. The endogenous peroxidase activity was blocked by incubating the slides in $3 \%$ hydrogen peroxide for 5 to $10 \mathrm{~min}$, and then washed in buffer. This is followed by incubation with the primary antibody (arginase-1) for one hour at room temperature. The antibody reaction was detected with the avidinbiotin detection kit using Diaminobenzidine (DAB) as chromogen. Sections were counterstained with hematoxylin for 15 seconds before checked under microscope. Normal liver tissues was used as positive control, while negative control was done using the same tissue (normal liver), omitting the primary antibody. All steps were performed in a humidity chamber to prevent drying of the tissues [23].

Only cytoplasmic or cytoplasmic and nuclear reactivity was considered as positive staining for arginase-1. Immunoreactivity was observed by two pathologists.

\section{Morphometric study}

Using Leica Qwin 500LTD (Cambridge UK) computer assisted image analyzer. Area percentage of Arginase-1 immunopositive cells were measured in liver sections for all groups. The measurements were done in 10 high power fields (HPF) using binary mode.

\section{Serum biochemical assessment}

Venous blood was withdrawn from the rats retro-orbital veins 
Citation: Ragaei A, Mansy A, Sabry D (2016) Therapeutic Potential of Mesenchymal Stem Cells and Vitamin E on Experimental Hepatocellular Carcinoma. J Stem Cell Res Ther 6: 362. doi: 10.4172/2157-7633.1000362

Page 3 of 9

of all groups to assess serum albumin and $\alpha$-fetoprotein (AFP) using colorimeter kits (Randox laboratories limited, Country Antrim, UK) and ELISA (provided by Diagnostic Systems Laboratories, Inc., Webstar, Texas, USA.) respectively according to manufacture instructions.

\section{Statistical analysis}

Statistical analysis was carried out using SPSS v. 15 software. All data were expressed as means \pm standard error of mean (SEM). Data were analyzed by one-way analysis of variance (ANOVA). Individual comparisons were made by Duncan's multiple range test using post hoc test of one-way ANOVA to determine the similarities and differences of mean values between different groups significantly. $\mathrm{P}$ values of less than 0.05 were considered statistically significant [24].

\section{Results}

\section{Stem cells characterization}

Under an inverted microscope (Leica, Germany) undifferentiated (h-AMSCs) were typical of adherent spindle and fibrocyte-like at one week culture and reached $80-90 \%$ confluence at 2 weeks culture (Figures $1 \mathrm{~A}$ and $1 \mathrm{~B}$ respectively). Flow cytometric analysis of the MSCs at the 4th passage showed that these cells were positive for CD105 (97.99\%) and negative expression of hematopoietic/endothelial markers CD45 (1.34\%) and CD133 (1.44\%) (data not shown). These results indicated that relatively purified (h-AMSCs) were isolated. Before cells injection, GFP-labeled h-AMSCs were analyzed and confirmed for their green auto fluorescence for in vivo cells tracing (Figure 2A). Frozen sections of h-MSCs injected liver tissues in all rats groups showed that the GFP-labeled cells were integrated within liver tissues (Figure 2B). That finding indicated homing of h-MSCs to injured liver tissues.

\section{Histopathological changes}

H\&E stain: Examination of the liver sections of adult control rats group (1) showed normal hepatic architecture, with hepatic cords radiating from the central vein extending toward the portal tract and separated by hepatic sinusoids. The hepatocytes formed a pericentral zone around the central vein and a periportal zone around the portal tract. They appeared polygonal and contained granular acidophilic cytoplasm and rounded vesicular nuclei. Some hepatocytes were binucleated (Figure 3).

Alternatively histopathology of liver tissues of adult rats of group (2): HCC induced group, showed regenerative nodules surrounded by fibrotic tissue, chronic inflammatory infiltrate with proliferating small bile ducts and hepatocytes showed fatty degeneration with vacuolated cytoplasm (Figure 4A).

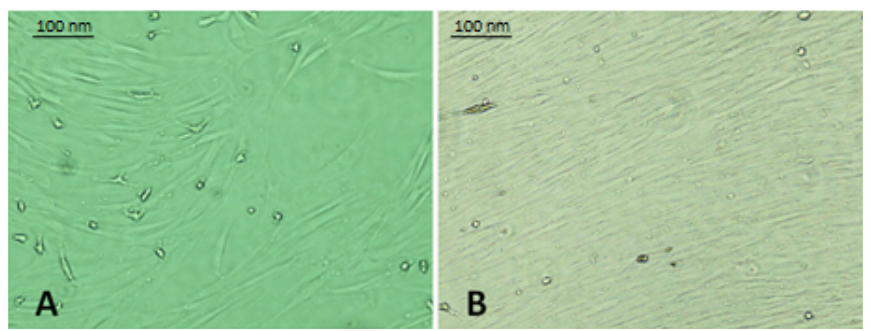

Figure 1: (A): h-AMSCs at one week of culture $(30-40 \%$ confluent), (B): h-AMSCs at two weeks of culture (80-90\% confluent).
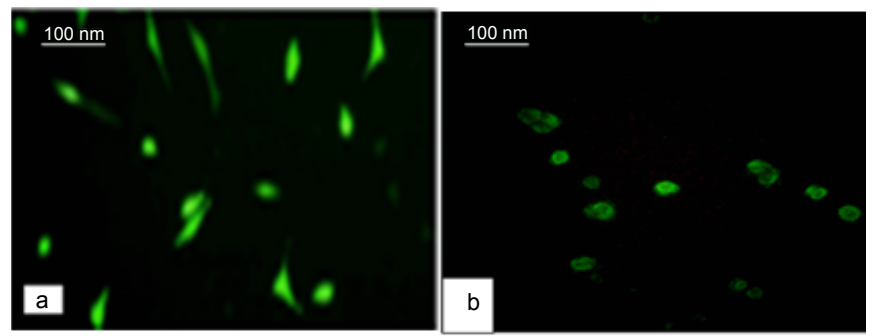

Figure 2: (A): Labeling of h-AMSCs with GFP fluorescent dye (in vitro), (B): Homing of the injected labelled mesenchymal stem cells by detecting GFP fluorescent dye in the rat liver (in vivo) 5 months post experimental duration.

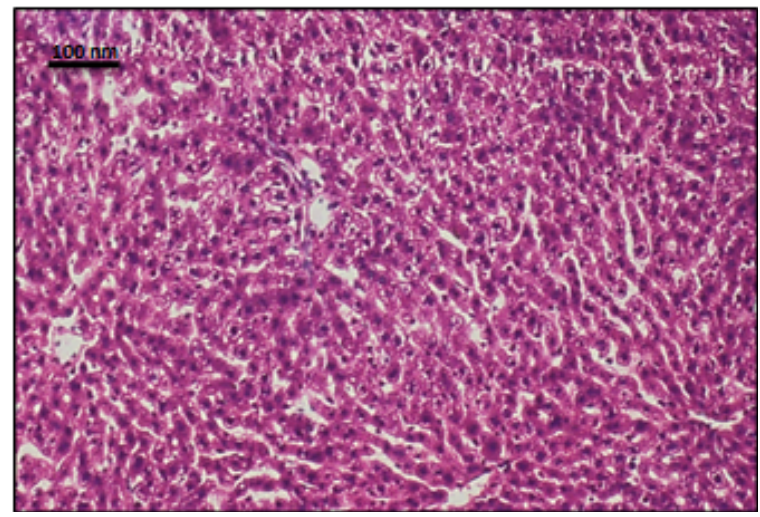

Figure 3: Photomicrograph of liver tissue of adult rat (Group 1: Control group) showing normal hepatic architecture (H\&E; 200X).

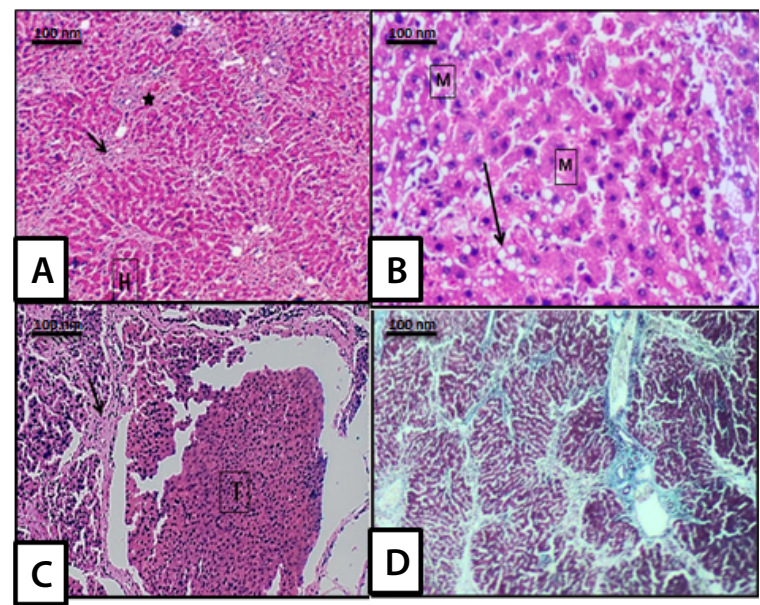

Figure 4: Photomicrograph of liver tissue of adult rat (Group 2: HCC-induced group): (A) after 2 months showing regenerative nodules surrounded by fibrotic tissue (arrow), proliferating bile ducts $(\downarrow)$ and hepatocytes showing hydropic changes $(H)$. (B) after 3 months showing malignant cells $(M)$ with variable degrees of cellular atypia and a lots of fatty vacuoles (arrow). (C) after 5 months showing solid growth pattern $(T)$ surrounded by thick fibrous bands (arrow) (H\&E; 200X) and (D) after 5 months showing a solid growth pattern with large tumor nodules separated by thick fibrous bands (Masson trichrome; 200X).

Three months post HCC induction, liver tissues of adult rats group (2): Showed hepatocytes with lots of fatty vacuoles, small groups of polymorphic, hyperchromatic malignant hepatocytes with moderate cellular and nuclear atypia (Figure 4B). After five months post HCC 
Citation: Ragaei A, Mansy A, Sabry D (2016) Therapeutic Potential of Mesenchymal Stem Cells and Vitamin E on Experimental Hepatocellular Carcinoma. J Stem Cell Res Ther 6: 362. doi: 10.4172/2157-7633.1000362

induction, liver tissues of the same group showed solid growth pattern in the form of large tumor nodules surrounded by thick fibrous bands. The malignant nature of such tumor gives a complete destruction of the original liver architecture (Figures 4C and 4D).

Improvement of histopathological picture after one month post h-AMSCst reatment, group (3): The liver tissue of adult rat of this group revealed moderate reversible hepatocytes damage and reduced fibrotic thickening surrounding the portal tracts. Some areas showed mild degenerative changes with presence of some inflammatory infiltrates and few neoplastic cells (Figure 5A). After 5 month post h-AMSCs treatment, liver tissue of the same group showed normal architecture with few degenerated areas and congestion between sinusoids were perceived (Figure 5B).

Liver tissues of group (4) (treated with Vit. E): Showed mild recovery with new cell formation appeared limited to the marginal parts of the liver tissue. All the examined specimens of this group, showed many degenerated areas fatty replacements, dilated sinusoids and venous congestion. Some promising regenerative areas were perceived (Figures $6 \mathrm{~A}$ and $6 \mathrm{~B}$ ).

Rat liver tissues in group (5) (HCC treated with h-AMSCs and Vit. E): Were attained the best results in comparison to all other treated groups. The liver tissues showed preserved liver architecture with normal appearance. Hepatocytes were radially arranged from central vein with eosinophilic cytoplasm and central basophilic nuclei No mononuclear inflammatory infiltrate was observed. Slight dilation of some sinusoids and mild degenerated areas were determined (Figures $7 \mathrm{~A}$ and $7 \mathrm{~B})$.

Masson's trichromestain: Examination of liver sections of the control group(1) of adult rats, showed minimal collagen fibers around central vein. Group (2) HCC induced without treatment, showed apparent increase in collagen fibers content. It was observed around tumor nodules in the form of thick blue fibrous bans separating the nodules from one another (Figure 4D).

\section{Immuno-histo chemical stain}

Anti-arginase-1 stained liver sections: Liver sections of control group (1): revealed brown immune-positive staining in the cytoplasm in all cells of the liver tissue (Figure 8A). Group (2) (HCC induced): revealed apparently increased immune-positive reactivity of arginase-1 in nucleus and cytoplasm as compared to control group and all other experimental groups (Figure 8B). However group (3) (HCC treated with h-AMCs) and group (4) (HCC treated with Vit E): showed arginas-1 immuno-positive staining in malignant cells only (Figures

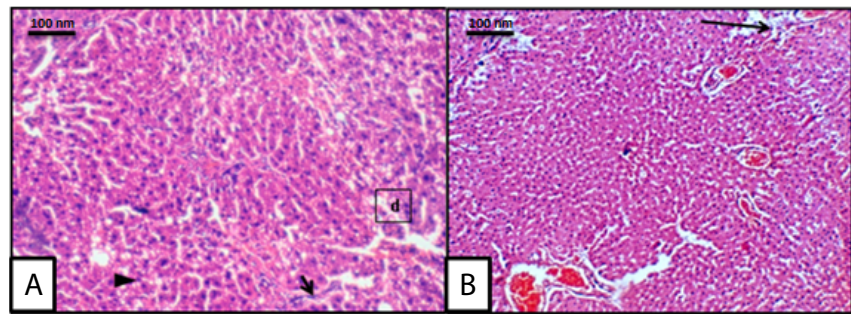

Figure 5: Photomicrograph of liver tissue of adult rat (Group 3: HCCgroup treated with h-AMSCs): (A) after 3 months showing moderate reversible liver cell damage in the form of degeneration (d) with presence of some inflammatory infiltrates (arrow) and neoplastic cells (arrow head). (B) after 5 months post treatment liver tissue showed normal architecture with few degenerated areas (arrow) and congestion (H\&E; 200X).

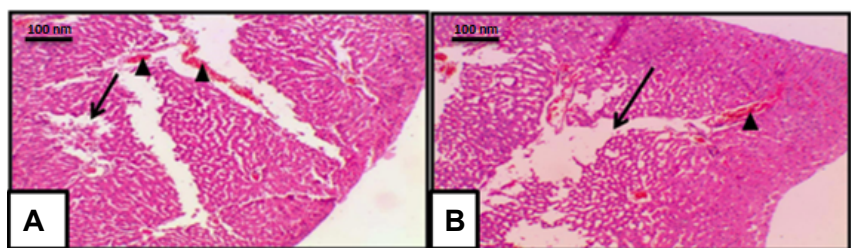

Figure 6: Photomicrograph of liver tissue of adult rat (Group 4: HCC group treated with Vit. E): (A and B) after 5 months showing lots of degenerated areas (arrow), dilated sinusoid and venous congestion (arrow heads) (H\&E; 200X).

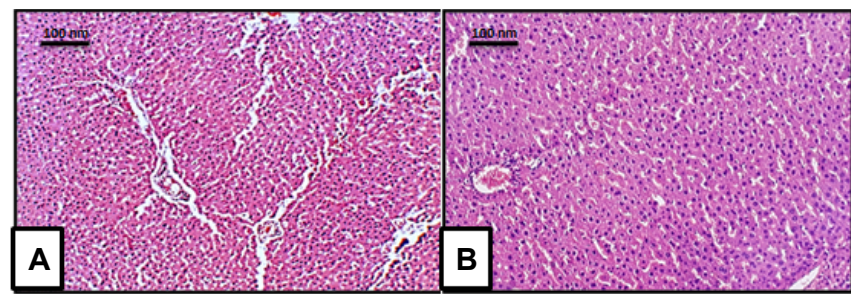

Figure 7: Photomicrograph of liver tissue of adult rat (Group 4: HCC group treated with h-AMSCs and Vit. E): (A) after 4 months showing more or less normal liver architecture; mild degenerated areas are still observed. (B) after 5 months showing readily arranged hepatocytes with eosinophilic cytoplasm and central basophilic nuclei (H\&E; 200X).

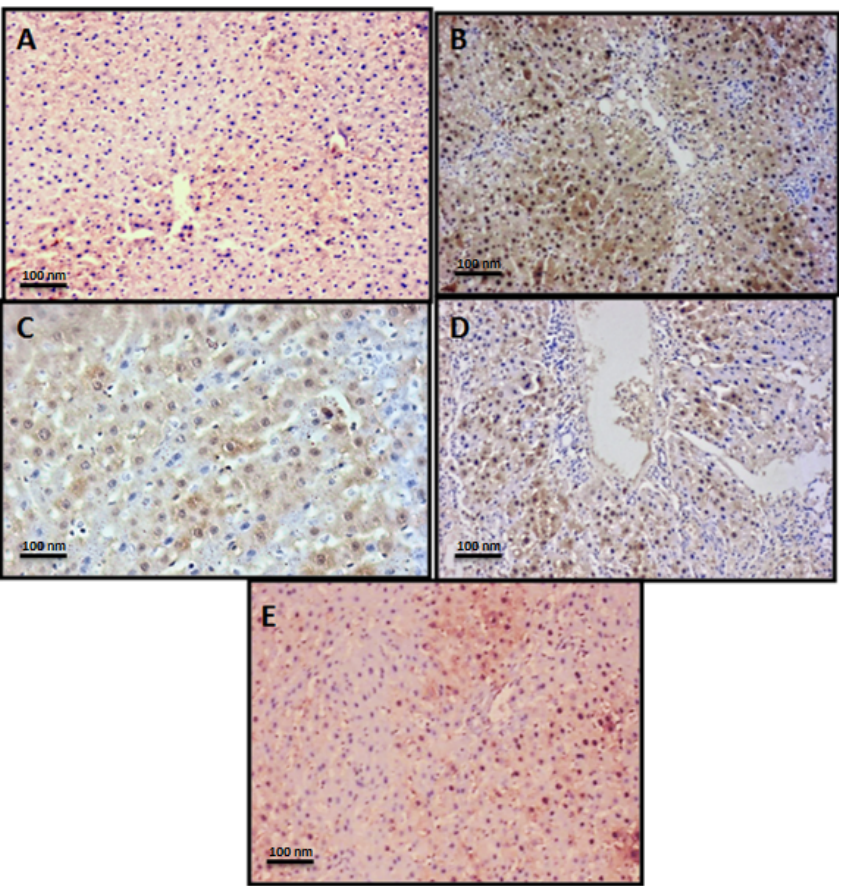

Figure 8: Photomicrograph of liver tissue in all studied groups at five months post experimental duration showing difference in immune-positive stain of anti-arginase- 1 in nucleus and cytoplasm of the hepatocytes denotes increase of reactivity in $\mathrm{HCC}$ group (2) (Figure 8B) more than control group (1) (Figure $8 \mathrm{~A}$ ), while HCC treated with h-AMSCs group (3) (Figure $8 \mathrm{C}$ ) and HCC treated with Vit $\mathrm{E}$ group (4) (Figure $8 \mathrm{D}$ ) showed arginase-1 positive reactivity only in neoplastic cells similar to control group (1) and HCC treated with h-AMSCs and Vit. E group (5) (Figure 8E). (Anti-arginase; 200X).

$8 \mathrm{C}$ and $8 \mathrm{D}$ respectively). There was no obvious difference in immunepositive staining between group (5) (HCC treated with h-AMSCs and Vit E) and control group (Figure 8E). 
Citation: Ragaei A, Mansy A, Sabry D (2016) Therapeutic Potential of Mesenchymal Stem Cells and Vitamin E on Experimental Hepatocellular Carcinoma. J Stem Cell Res Ther 6: 362. doi: 10.4172/2157-7633.1000362

Page 5 of 9

The above findings proved the specificity of anti-arginase- 1 stain for early diagnosis of HCC and the therapeutic potential effect of h-AMSCs and Vit. E in treatment of induced HCC. The mean percent area of arginase-1 positive hepatocytes in all studied groups was presented in Figure 9. The highest percent area for arginase-1 positive hepatocytes was in HCC induced group.

\section{Laboratory investigations}

Measurements of serum albumin level in all the studied groups were shown in Table 1 . There was no significant difference in the mean albumin levels between HCC treated group with combined MSCs and Vit $\mathrm{E}$ and control group. The mean serum albumin in HCC group showed a significant decrease $(\mathrm{p}>0.05)$ when compared to control group, HCC group treated with MSCs and HCC group treated with combined MSCs and Vit E. The mean serum albumin level in HCC group treated with MSCs showed a significant increase when compared to HCC group treated with Vit. E on 5 months post-treatment duration (Figure 10).

Measurements of serum AFP level in all studied groups were shown in Table 2. There was no significant difference in the mean AFP level in control, HCC treated with MSCs and HCC treated with combined MSCs and Vit E. The mean serum AFP in HCC group showed highly significant increase $(p>0.05)$ when compared to all other groups. Mean serum level of AFP in Vit.E treated group showed a significant decrease when compared to control, HCC treated with MSCs and HCC treated with combined MSCs and Vit E. (Figure 11).

\section{Mean area \% of Agrinase-I positive immune hepatocytes in all groups}

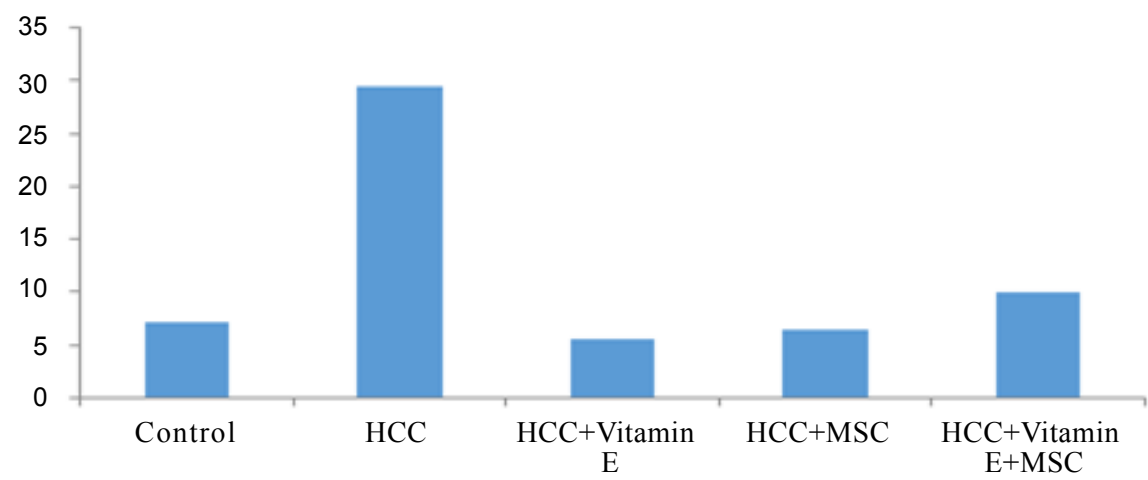

Figure 9: Histogram comparing the mean area percent of arginase-1 immuno-positive cells in the control and experimental groups.

\begin{tabular}{|c|c|c|c|c|c|}
\hline Groups Months & Control & $\mathrm{HCC}$ & HCC+MSC & HCC+Vit E & HCC+Vit E+MSC \\
\hline 3 & $4 \pm 0.194^{\mathrm{ad}}$ & $2.22 \pm 0.305^{b}$ & $2.84 \pm 0.261^{b c}$ & $3.44 \pm 0.177^{\mathrm{ac}}$ & $4.24 \pm 0.163^{d}$ \\
\hline 4 & $4.04 \pm 0.369^{a}$ & $1.256 \pm 0.169^{b}$ & $2.52 \pm 0.302^{c}$ & $3.22 \pm 0.272^{c}$ & $4.14 \pm 0.081^{a}$ \\
\hline 5 & $4.26 \pm 0.150^{a}$ & $1.054 \pm 0.037^{b}$ & $3.5 \pm 0.294^{d}$ & $2.58 \pm 0.152^{c}$ & $4.64 \pm 0.237^{a}$ \\
\hline
\end{tabular}

Values are mean \pm SEM

Values with different superscript letters are significantly different $(P<0.05)$.

Table 1: Albumin level $(\mathrm{g} / \mathrm{dl})$ in all studied groups in different months.

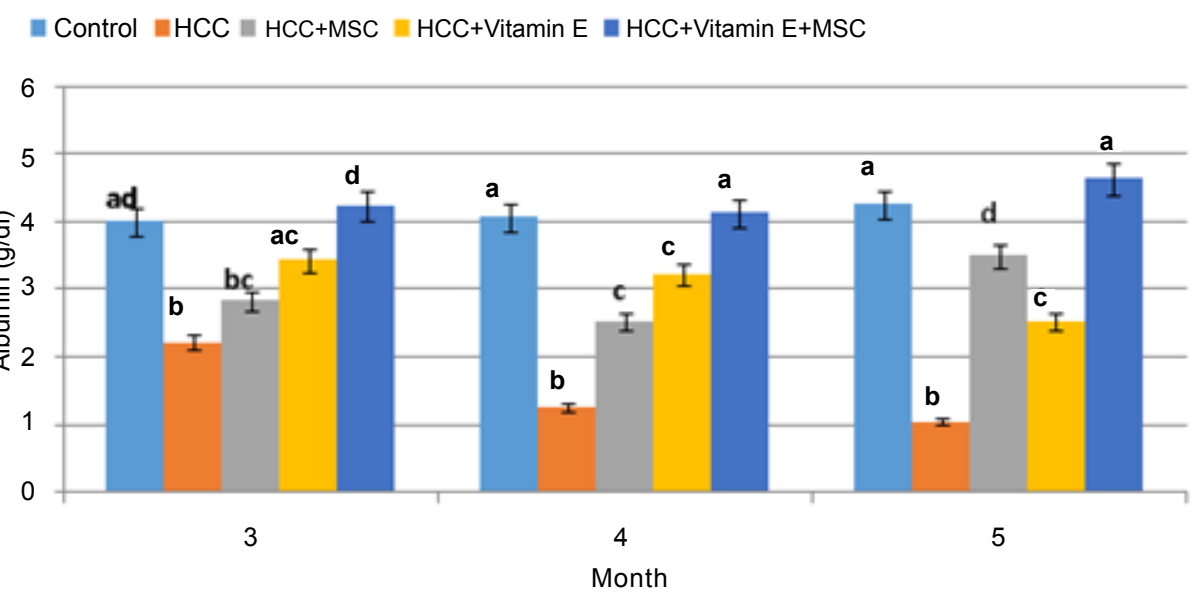

Figure 10: Showed histogram presented the different concentrations of albumin in plasma of rats in all treated groups compared to normal control and all treated groups. 


\begin{tabular}{|c|c|c|c|c|}
\hline Groups Months & Control & HCC & HCC+MSC & HCC+Vit E \\
\hline 3 & $4.084 \pm 0.187^{\mathrm{a}}$ & $35.12 \pm 5.8^{\mathrm{b}}$ & $4.538 \pm 1.017^{\mathrm{a}}$ & $6.58 \pm 1.013^{\mathrm{a}}$ \\
\hline 4 & $2.952 \pm 0.087^{\mathrm{a}}$ & $54.94 \pm 1.953^{\mathrm{b}}$ & $3.252 \pm 0.356^{\mathrm{a}}$ & $4.88 \pm 1.160^{\mathrm{a}}$ \\
\hline 5 & $3 \pm 0.213^{\mathrm{ac}}$ & $54.42 \pm 0.644^{\mathrm{b}}$ & $3.37 \pm 0.340^{\mathrm{c}}$ & $2.78 \pm 0.281^{\mathrm{a}}$ \\
\hline
\end{tabular}

Values are mean \pm SEM

Values with different superscript letters are significantly different $(P<0.05)$.

Table 2: Showed AFP level $(\mathrm{ng} / \mathrm{ml})$ in all studied group in different months.

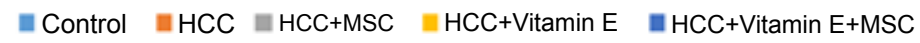

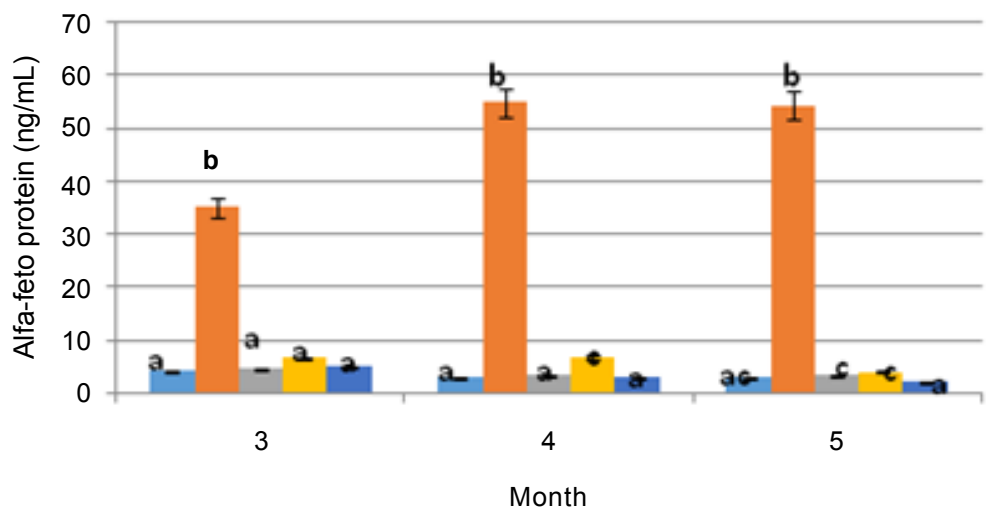

Figure 11: Showed histogram presented the different concentrations of AFP in plasma of rats in all treated groups compared to normal control and all treated groups

\section{Discussion}

Malignant hepatocytes transformation may occur through repetitive liver injury in a context of inflammation, cirrhosis and oxidative DNA damage [25]. MSCs can represent a hope for cancer therapies through their potential of inhibiting tumor cells from regeneration in different types of animal models [26]. Human bone marrow MSCs home to sites of hepatocellular carcinoma in rats and were able to suppress hepatocarcinogensis [27].

In the present study we aimed at using human amniotic MSCs (h-AMSCs) as a new approach in studying their effect in HCC therapy. It has been reported that (h-AMSCs) consistently express CK18 over a long period of culture and furthermore they can express AFP and HNF-4a during the later passages of culture [28]. Consequently, it was hypothesized that they can be easily differentiated into hepatic lineage cells. h-AMSCs have been shown to exhibit high differentiation potential and high proliferative activity, both characteristics of stemness [29,30]. Regarding the immunophenotype, h-AMSCs place themselves once again between adult MSCs and ESCs, since they are positive for surface markers characteristic of mesenchymal and/or neural stem cells and also express Octamer Binding Transcription Factor (OCT4), NANOG and Stage-Specific Embryonic Antigen-4 (SSEA-4). For instance, they were induced to undergo adipogenic, osteogenic, neurogenic differentiation and oocytes like cells [31]. Moreover, h-AMSCs expressing the stem cell marker OCT4, they can differentiate into cells of all three embryonic tissue layers [30,32].

In the present study h-AMSCs were identified by detection of CD105 surface marker, their fusiform shape, adherence and their ability to differentiate into osteocytes and adipocytes. Homing of h-AMSCs in liver was confirmed byhoming of MSCs labeled by GFP in injured liver. Experimental findings suggested that the induction of parenchymal damage is a prerequisite for successful homing and repopulation with stem cells [33].
Histopathological examination of liver tissues in group2 that received DENA and CCL4 was the only one which revealed development of HCC, this was shown by the presence of tumor nodules formed of solid cords, small groups of polymorphic, hyperchromatic malignant hepatocytes with moderate cellular and nuclear atypia. On the other hand, injection of h-AMSCs in HCC induced rats, led to the improvement of the histopathological picture with minimal reversible liver cell damage represented in the form of degenerative areas, dysplastic hepatocytes along with a great part of the tissue showing normal liver architecture, few malignant cells were still observed in groups ( 3 and 4 ). These results reinforced by the suggestion of previous studies constitute the first evidence, that h-AMSCs have the potential to survive and integrate into the adult mouse liver and to differentiate into functional hepatocytes [34]. This confirms the potential role of h-AMSCs as an effective stem cell based therapy. It has been reported that cells derived from amniotic fluid can integrate into an area of tissue damage and express markers specific to the target cell lineage in rodent models of lung and brain injury [35]. Furthermore it was previously published that transplanted hAMSCs can survive for more than 90 days in injured tissues which give a prolonged duration for easier regeneration and tissue repair [36].

h-AMSCs and Vitamin E treated group showed the best results over all experimental groups. Histological features of the liver tissues in animals treated with combined h-MSCs and Vit. E resemble to a greater extent to that of normal control. These findings suggested that, the oral administration of Vitamin E together with h-AMSCs may increase the efficiency of the stem cells by increasing their proliferative effect.

The co-supplementation of Vit. E with h-AMSCs, prevented free radicals induced damage to the liver tissues, by avoiding lipid per-oxidation through scavenging hydroxyl radical and enhancing immune responses. Furthermore, it increased their ability of inhibiting oxidative DNA damage of regenerated cells, thus giving excellent 
results in controlling HCC induced in that group [37]. The increased resistance to oxidative stress detected in cells expressing MDR phenotype is most likely due to an increase in antioxidant defense of Vit. E provided in the treatment. As Vitamin E has a role in decreasing the over-expression of P-glycoprotein functions as an ATP dependent efflux pump that extrudes cytotoxic drugs from inside of tumor cells [38,39]. Vitamin E played an obvious role resulted in a significant reduction of chromosomal damage and prevention of hepatic tumor formation [18].

The histopathological results of liver tissue in Vit. E treated group after induction of HCC showing minimal tissue recoveryand that lead us to the discovery that Vit. E alone can't regulate the damage caused by DENA and $\mathrm{CCl}_{4}$.

The decreased serum levels of AFP and increased albumin levels in HCC group treated with h-AMSCs and Vitamin E in comparison to all other groups, indicate their efficacy in amelioration of the malignant status as well as improving the liver function of HCC model.

Many studies have reported the inhibition of albumin in hepatocarcinogensis [40]. In general, the incidence of hepatocellular carcinoma recurrence is high in patient with advanced liver fibrosis [41]. In vitro and in vivo studies have demonstrated that Vit. E promotes albumin synthesis. Recent studies showed that increase in albumin level with reduced AFP expression because expecting that Vit E would inhibit hepatocyte proliferation and hence hepatocarcinogensis [42].

On the other hand, albumin inhibited the phosphorlylation of $\mathrm{Rb}$ proteins P 780 and P807/811. Furthermore, the expression of p21 and p57 increases significantly in the presence of albumin, suggesting that albumin induces the expression of $\mathrm{P} 21$ and $\mathrm{P} 57$ to inhibit Rb protein phosphorylation, thereby arresting the cell cycle in the G1 phase. These results suggest that the albumin itself suppresses the proliferation of hepatocellular carcinomas [43].

In the present study arginase-1 immunostaining was used as sensitive and specific IHC biomarker for hepatocellular neoplasms. The increased Agr-1 immunostaining which was recorded in HCC induced group more than control and other groups, aid on verifying that the induced lesions were HCC. However control group showed positive Arg-1 in cytoplasm only without showing any positive reaction in the nucleus of all cells. On the other hand all other treated groups showed positive cytoplasmic and nuclear immuniostaing only in neoplastic cells. The obtained results coincide with the findings of other investigators, who reported the high expression of Arg- 1 immuniostain with high sensitivity and specificity for HCCs ranging from $96.0 \%$ $99.0 \%$ respectively [23].

The increase in Arg-1 immuniostaing in neoplastic cells was greater than normal value and it is worth mentioning that the caused inborn error in urea cycle was the main factor that caused increased hepatocyte damage due to the high liver toxicity.

Recent studies has postulated that the essential role of stem cells microenvironment niche in preventing carcinogensisis by providing signals to inhibit proliferation and promote cell differentiation [44]. Our evidence was in postulating that microvesicles tumor cells secreting proteins can activate signaling pathways facilitating h-AMSCs migration to tumor site and the destruction of tumor cells.

Meanwhile the surface marker profile of h-AMSCs cells and their expression of the transcription factor Oct4 advocate that they represent an intermediate stage between pluripotent ES cells and lineage-restricted adult stem cells. In addition to their low potentiality in inducing tumor in vivo, giving them great advantage to be used as cell based therapy agent in our study.

Most current strategies in cell therapy and tissue engineering were to use cells obtained from biopsies of patient's tissues. However, for some applications autologous cells from an appropriate tissue cannot be readily obtained or expanded in culture. Stem cell lines that can be propagated easily with maintained genetic stability, and can be induced to differentiate into desired specialized cells may offer an alternative source [29].

The use of h-AMSCs in the present study is for the acquisition of lineage-specific functionality of these cells differentiated in vitro hepatocyte-like cells.

Several novel findings regarding role of MSCs in cancer development and/or therapy are summarized from several studies [45]: MSCs can behave as potent antigen-presenting cell (APCs) and could be exploited as new therapeutic tool in cancer therapy in order to amplify immune responses against tumor-specific antigens [46].

It was recently demonstrated that MSCs had potential inhibitory effects on tumor cell growth in vitro and vivo without immunosuppression, by inducing apoptotic cell death and G0/G1 phase arrest of cancer cells [47].

According to the above mentioned basis it was reported that MSCs help in the arresting of cancer cell cycle and the increase of albumin concentration in serum blood by the help of Vitamin E administration which had in turn arrested Glphase of malignant cells stopping its proliferation. h-AMSCs together with Vitamin E could be a promising treatment in HCC.

An increasing number of reports have suggested that Microvesicles (MVs) derived from MSCs, which are therapeutically beneficial as a treatment, can serve as a cell free regenerative option for multiple diseases [48]. This is due to the fact that MVs contain a variety of molecules, including proteins, microRNAs, and mRNAs, and are associated with biological processes in a content molecule-dependent manner [49].

For my own knowledge this is the first molecular research to study influence of combined MSCs and Vit. E treatment and using the arginase- 1 as an early diagnostic biomarker tool in experimental induced HCC.

In conclusion, the present findings demonstrated that h-AMSCs and Vitamin $\mathrm{E}$ have tumor suppressive effect in chemically induced hepatocarcinogensis as evidenced by using argainse-1 sensitive immunohistochemistry biomarker for early diagnosis of HCC. Further studies are recommended regarding different signaling effects of h-AMSCs derived microvesicles as considering that, microvesicles are the new theoretical mechanisms in biological therapeutic effects of MSCs. Above and beyond, future studies should be directed at the studying and identification of molecular role of Vitamin $\mathrm{E}$ in prevention of HCC.

\section{References}

1. Jemal A, Bray F, Center MM, Ferlay J, Ward E, et al. (2011) Global cancer statistics. CA Cancer J Clin 61: 69-90. [PubMed]

2. Linda DF, Robert DO, Goldblum JR (2009) Benign and malignant tumors of the liver Biliary Tract, and Pancreas. 2nd ed Surgical Pathology of the GI Tract: Philadelphia, PA: W.B. Saunders pp: 1291-1325.

3. Anwar WA, Khaled HM, Amra HA, El-Nezami H, Loffredo CA (2008) Changing pattern of hepatocellular carcinoma $(\mathrm{HCC})$ and its risk factors in Egypt: possibilities for prevention. Mutat Res 659: 176-184. [PubMed] 
Citation: Ragaei A, Mansy A, Sabry D (2016) Therapeutic Potential of Mesenchymal Stem Cells and Vitamin E on Experimental Hepatocellular Carcinoma. J Stem Cell Res Ther 6: 362. doi: 10.4172/2157-7633.1000362

4. Shirakami Y, Gottesman ME, Blaner WS (2012) Diethylnitrosamine-induced hepatocarcinogenesis is suppressed in lecithin-retinol acyltransferase-deficient mice primarily through retinoid actions after carcinogenic administration. Carcinogenesis 33: 268-274. [PubMed]

5. Yan BC, Gong C, Song J, Krausz T, Tretiakova M, et al. (2010) Arginase-1: a newimmunohistochemical marker of hepatocytes and hepatocellular neoplasms. Am J Surg Pathol 34: 1147-1154. [PubMed]

6. Choi S, Park C, Ahn M, Lee JH, Shin T (2012) Immunohistochemical study of arginase 1 and 2 in various tissues of rats. ActaHistochem 114: 487-494. [PubMed]

7. Aziz TA, Mohamed F, Hazem M , Soheir M , Hanan H , et al. (2011) Efficacy of Mesenchymal Stem Cells in Suppression of Hepatocarcinorigenesis in Rats: Possible Role of Wnt Signaling. J Exp Clin Cancer Res 30: 49. [PubMed]

8. Mohamed T, Nagwa R, Laila A, Dina S, Amira A, et al. (2011) Effect of human mesenchymal stem cells on hepatoma cell line. Journal of Stem Cell Studies 1: $84-88$

9. Qiang Y, Liang G, Yu L (2016) Human amniotic mesenchymal stem cells alleviate lung injury induced by ischemia and reperfusionafter cardiopulmonary bypass in dogs. Lab Invest 96: 537-46. [PubMed]

10. Maestroni GJ, Hertens E, Galli P (1999) Factor(s) from nonmacrophage bone marrow stromal cells inhibit Lewis lung carcinoma and B16 melanoma growth in mice. Cell Mol Life Sci 55: 663-667. [PubMed]

11. Gunawardena K, Murray DK, Meikle AW (2000) Vitamin E and other antioxidants inhibit human prostate cancer cells through apoptosis. Prostate 44: 287-295. [PubMed]

12. Benfeito S, Oliveira C, Soares P, Fernandes C, Silva T, et al. (2013) Antioxidan therapy: still in search of the 'magic bullet'. Mitochondrion 13: 427-435. [PubMed]

13. Moonl, Xiaodong W, Marilyn E (2006) Dietary flavonoids Effects on xenobiotic and carcinogen metabolism. Toxicology in Vitro 20: 187-210 [PubMed]

14. Aggarwal BB, Sundaram C, Prasad S, Kannappan R (2010) Tocotrienols, the vitamin $E$ of the 21st century: its potential against cancer and other chronic diseases. BiochemPharmacol 80: 1613-1631. [PubMed]

15. Aziz MTA, El Asmar MF, Mostafa T, Atta H, Fouad HH, et al. (2007) Effect of hemin and carbon monoxide releasing molecule (CORM-3) on cGMP in rat penile tissue. J Sex Med 5: 336-43.

16. Aziz MTA, Khaled HM, El Hindawi A, Roshdy NK, Rashed LA, et al. (2013) Effect of mesenchymal stem cells and a novel curcumin derivative on Notch1 signaling in hepatoma cell line. Biomed Res Int 2013:129629. [PubMed]

17. Qiao L, Xu Z, Zhao Z, Zhao Z, Shi M, et al. (2008) Suppression of tumorigenesis by human Mesenchymal Stem Cells in a hepatoma model. Cell Res 18: 500507 [PubMed]

18. Ornella F, Maura L, Paola F, Marchettia S, Fabbroni V, et al. (2004) Vitamin E protect DNA from oxidative Damage in Human Hepatocellular Carcinoma Cell Lines. J Free Radical Research 38: 751-759. [PubMed]

19. Wang Z, Pal R (2014) Enlargment of Nanoemulsion Region in Pseudo-ternary Mixing Diagram for drug Delivery system. J surfact Deterg 17: 49-58.

20. Zhao W, Li J, Cao D, Li X, Zhang L, et al. (2012) Intravenous injection of mesenchymal stem cells is effective in treating liver fibrosis. World $\mathrm{J}$ Gastroenterol 18: 1048-1058. [PubMed]

21. Kiernan JA (2011) Histological and Histochemical methods: Theory and Practice. 3rd ed. London, New York and NewDelhi Arnold Publisher pp: 111 162

22. Bancroft JD, Gamble M (2008) Connective tissue stain. In Theory and Practice of Histological Techniques. 6th ed. Edinburgh, London, Oxford, New York, Philadelphia, St Louis, Sydney and Toronto: Elsevier Health Sciences, Churchill Livingstone p: 150.

23. Yan BC, Gong C, Song J, Krausz T, Tretiakova M, et al. (2010) Arginase1; a new immunohistochemical marker of hepatocytes and hepatocellular neoplasm. Am J SurgPathol 34: 1147-1154. [PubMed]

24. Duncan DB (1955) Multiple range and multiple F tests. Biometrics 11: 1-42.

25. Levrrero M (2006) Viral hepatitis and liver cancer the cause of hepatits C Oncogene 25: 3834-3847. [PubMed]
26. Lazennec G, Jorgensen C (2008) Adult multipotent stromal cells and cancer: risk or benefit? Stem Cells 26: 1387-1394. [PubMed]

27. Maestroni GJ, Hertens E, Galli P (1999) Factor(s) from non macrophage bone marrow stromal cells inhibit Lewis lung carcinoma and B16 melanoma growth in mice. Cell Mol Life Sci 55: 663-667. [PubMed]

28. Kim J, Lee Y, Kim H, Hwang KJ, Kwon HC, et al. (2007) Human amniotic fluidderived stem cells have characteristics of multipotent stem cells. Cell Prolif 40 : 75-90. [PubMed]

29. De Coppi P, Bartsch G, Siddiqui MM, Xu T, Santos CC, et al. (2007) Isolation of amniotic stem cell lines with potential for therapy. Nat. Biotechnol 25: 100106. [PubMed]

30. Nicholas CR, Haston KM, Grewall AK (2009) Transplantation directs oocytematuration from embryonic stem cells and provides a therapeutic strategy for female infertility. Hum Mol Genet 18: 4376-4389. [PubMed]

31. Cheng X, Chen S, Yu X, Zheng P, Wang H (2012) BMP15 gene is activated duringhuman amniotic fluid stem cell differentiation into oocyte-like cells. DNA Cell Biol 31: 1198-1204. [PubMed]

32. Tanikawa M, Harada T, Ito M, Enatsu A, Iwabe T, et al. (2000) Presence of stem cell factor in follicular fluid and its expression in the human ovary. FertilSteril 73 1259-1260. [PubMed]

33. Schwartz RE, Reyes M, Koodie L, Jiang Y, Blackstad M, et al. (2002) Multipotent adult progenitor cellsfrom bone marrow differentiate into functional hepatocyte-like cells. J Clin Invest 109: 1291-1302. [PubMed]

34. Rosner M, Dolznig H, Schipany K, Longacre TA, ReijoPera RA (2011) Humanamniotic fluid stem cells as a model for functional studies of genes involved in human genetic diseases or oncogenesis. Oncotarget 2: 705-712 [PubMed]

35. Carraro G, Perin L, Sedrakyan S, Giuliani S, Tiozzo C, et al. (2008) Human amniotic fluid stem cells can integrate and differentiate into epithelial lung lineages. Stem Cells 26: 2902-2911. [PubMed]

36. Cipriani S, Bonini D, Marchina E, Balgkouranidou I, Caimi L, et al. (2007) Mesenchymal cells from human amniotic fluid survive and migrate after transplantationinto adult rat brain. Cell Biol Int 31: 845-850. [PubMed]

37. Duggan C, Gannon J, Walker WA (2002) Protective nutrients and functional foods for the gastrointestinal tract. Am J ClinNutr 75: 789-808. [PubMed]

38. Yachi R, Muto C, Ohtaka N, Aoki Y, Koike T, et al. (2013) Effect of tocotrienol on tumor necrosis factor -alpha/D-galactosamine induced steatohepatitis in rats. JclinBiochemNutr 52: 146-153. [PubMed]

39. Muto C, Yachi R, Aoki Y, Kokike T, Igarashi O, et al. (2013) Gamma-tocotrieno reduces the triaacyl glycerol level in rat primary hepatocytesThrough regulation of fatty acid metabolism. JclinBiochemNutr 52: 32-37. [PubMed]

40. Ikeda K, Arase Y, Saitoh S, Kobayashi M, Suzuki Y, et al. (2000) Interferon beta prevents recurrence of hepatocellular carcinoma after complete resection or ablation of the primary tumor-A prospective randomized study of hepatitis $\mathrm{C}$ virus-related liver cancer. Hepatology 32: 228-232. [PubMed]

41. Kubo S, Yamamoto T, Ikebe T, Shuto T, Hirohashi K (1999) Relationship between multicentric occurrence of hepatocellular carcinoma and histology of noncancerous hepatic tissue in patients with chronic hepatitis C. Jpn J Cancer Res 90: 1076-1080. [PubMed]

42. Kim RD, Stein GS, Chari RS (2001) Impact of cell swelling on proliferative signal transduction in the liver. J Cell Biochem 83: 56-69. [PubMed]

43. Shunsuke N, Taskashi J (2014) Albumin Suppresses Human Hepatocellular Carcinoma Proliferation and the Cell Cycle. Int J Mol Sci 15: 5163-5174. [PubMed]

44. Livraghi T, Meloni F, Frosi A (2005) Treatment with stem cell differentiation stage factors of intermediate-advanced hepatocellular carcinoma: an open randomized clinical trial. Oncol Res 15: 399-408 [PubMed]

45. Marini FC (2009) The complex love-hate relationship between mesenchymal stromal cells and tumors. Cytotherapy 11: 375-376. [PubMed]

46. Pommey S, Galipeau J (2006) The use of mesenchymal stromal cells inoncology and cell therapy. Bull Cancer 93: 901-907. [PubMed]

47. Lu YR, Yuan Y, Wang XJ, Wei LL, Chen YN, et al. (2008) The growth inhibitory effect of mesenchymal stem cells on tumor cells in vitro and in vivo. Cancer BiolTher 7: 245-251. [PubMed] 
Citation: Ragaei A, Mansy A, Sabry D (2016) Therapeutic Potential of Mesenchymal Stem Cells and Vitamin E on Experimental Hepatocellular Carcinoma. J Stem Cell Res Ther 6: 362. doi: 10.4172/2157-7633.1000362

48. Gennai S, Monsel A, Hao Q, Park J, Matthay M, et al. (2015) Microvesicles Derived from Human Mesenchymal Stem Cells Restore Alveolar Fluid Clearance in Human Lungs Rejected for Transplantation. Am J Transplant. 15: 2404-2412. [PubMed]
49. Lai RC, Yeo RW, Tan KH, Lim SK (2013) Exosomes for drug delivery - a novel application for the mesenchymal stem cell. Biotechnol Adv 31: 543-551. [PubMed] 